\title{
Does uranium exposure induce genotoxicity in the teleostean Danio rerio? First experimental results
}

\author{
S. Barillet ${ }^{1}$, A. Buet ${ }^{1}$, C. Adam ${ }^{1}$ and A. Devaux ${ }^{2}$ \\ ${ }^{1}$ Laboratory of Radioecology and Ecotoxicology, IRSN (Institute for Radioprotection \\ and Nuclear Safety), DEI/SECRE/LRE, Cadarache, Bd. 186, BP. 3, \\ 13115 St-Paul-Lez-Durance Cedex, France, e-mail: sabrina.barillet@irsn.fr \\ ${ }^{2}$ Environnemental Science Laboratory (LSE), ENTPE, 69518 Vaulx en Velin Cedex \\ and INRA, EFPA department, 34398 Montpellier Cedex 5, France
}

\begin{abstract}
Zebrafish were exposed to different concentrations of waterborne uranium (0, 20, 100

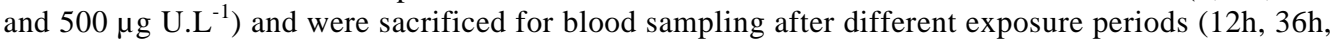
$72 \mathrm{~h}, 5,10$ and 20 days) in order to assess DNA integrity in erythrocytes, using the comet assay and flow cytometry. Concurrently, uranium bioaccumulation was studied in the remaining tissues to understand the potential genotoxic biomarker responses. Both genotoxic assays revealed significant effect of waterborne uranium on DNA integrity of fish erythrocytes. However, comet assay only succeeded in detecting such an effect after a 20-day exposure whereas flow cytometry analysis showed a uranium concentration effect for any exposure duration. Regarding uranium bioaccumulation, significant effects of both uranium concentration and exposure duration have been highlighted in this experiment.
\end{abstract}

\section{INTRODUCTION}

Within the Envirhom research program launched by IRSN in 2001, key advances have been obtained regarding uranium bioaccumulation and underlying mechanisms understanding in various biological models mainly at the individual level. However, considering different scales of biological effects (from early to delayed ones, from low to high level of organization) is crucial to provide ecologically relevant indicators. Organisms counteract stress induced by pollutant exposure through a wide range of physiological responses being both dose and time dependent. Effects at higher hierarchical levels are always preceded by early changes in biological processes, from subtle biochemical disturbances to impaired physiological functions, increased susceptibility to other stresses, reduced life-span.

In regard to chemotoxic and radiotoxic uranium properties, genotoxicity seems to be a relevant endpoint among the subsequent primary subcellular damages. Indeed, uranium is categorized as a heavy metal with a radiotoxic potential, it is the heaviest naturally occurring element and its typical concentration range in surface waters is $3.10^{-2}$ to $2 \mu \mathrm{g} / \mathrm{L}$ [1]. Considering uranium chemical characteristics, as any heavy metal, this radioelement is a potent genotoxic compound via the formation of oxidative DNA damages due to the redox chemistry of transition metals and their ability to activate oxygen species in the course of redox reactions [2][3]. In the same way, its radiological properties being characterized by ionising radiations (mainly via the emission of $\alpha$ particles) can enhance this free radical production [4]. Thereby there is a need of knowledge of the understanding of U-living organisms interactions to provide useful tools for predicting possible genotoxic effects of environmental uranium exposure. 
Fish are useful sentinels to detect environmental hazards, and as efficient and cost-effective model systems they have been selected for mechanistic toxicology and risk assessment studies for many decades. Among them, zebrafish has been preferred as a model organism in various ecotoxicological studies due to numerous advantages. Indeed, zebrafish are easily housed, breed continuously year-round and have short generation times. Furthermore, since their small size minimizes the cost and waste volume for toxicants, more and more studies now use this model organism thus increasing the pool of data available on it [5].

Preliminary experiments were thus carried out on adult zebrafish (Danio rerio), to assess early changes induced by uranium exposure via the direct route. Animals were exposed to different concentrations of waterborne uranium and were sacrificed for blood sampling after different exposure periods in order to assess DNA integrity of their erythrocytes, using the comet assay and flow cytometry. Concurrently, uranium bioaccumulation was studied in the remaining tissues to understand the potential genotoxic biomarker responses.

\section{MATERIALS \& METHODS}

\subsection{Animal maintenance}

Zebrafish (Danio rerio) of both sexes weighing 0.2 to $0.6 \mathrm{~g}$ were obtained from a local hatchery (Aquasem, France) and acclimatized to laboratory conditions for several days before experiment. During acclimatization and experiment phases, animals were kept at a maximal density of 5 fish/L in 4 tanks filled with $80 \mathrm{~L}$ of water. They were daily supplied with standard fish pellets $(1 \%$ of their body mass per day) and kept at $25^{\circ} \mathrm{C}$ in artificial water equilibrated by air-bubbling and continuously renewed by means of a flowthrough water system. Ion concentrations in synthetic water were as follows: $6.26 \mathrm{mg} / \mathrm{L} \mathrm{K}^{+}, 11.5 \mathrm{mg} / \mathrm{L} \mathrm{Na}^{+}, 4.74 \mathrm{mg} / \mathrm{L} \mathrm{Mg}^{2+}, 11.6 \mathrm{mg} / \mathrm{L} \mathrm{Ca}^{2+}, 32.4 \mathrm{mg} / \mathrm{L} \mathrm{Cl}^{-}, 31.0 \mathrm{mg} / \mathrm{L} \mathrm{NO}_{3}{ }^{-}$, $9.61 \mathrm{mg} / \mathrm{L} \mathrm{SO}_{4}{ }^{2-}, 0.45 \mathrm{mg} / \mathrm{L} \mathrm{CO}_{3}{ }^{2-}$. The $\mathrm{pH}$ was regulated at a value of 6.5 by the addition of $\mathrm{HCl}$ via peristaltic pumps controlled by pH stats (Consort R301, Illkirch, Belgium)

\subsection{Chemicals}

Uranyl nitrate solution, $\mathrm{UO}_{2}\left(\mathrm{NO}_{3}\right)_{2} \cdot 6 \mathrm{H}_{2} \mathrm{O}$, was obtained at Fluka (Buchs, Switzerland) and all other reagents of analytical grade were supplied by Sigma Chemicals (St Quentin Fallavier, France).

\subsection{Exposure conditions}

During the experiment, fish were exposed to four different uranium concentrations in the water (no added U, 20, 100 and $500 \mu \mathrm{g} / \mathrm{L}$ ) and were sampled at 12h, 36h, 72h, 5, 10 and 20 days. Thus, fish were equally distributed in each of the four tanks (each one being devoted to a given uranium concentration) and were then sub-distributed in six different groups per tank, physically separated by wire fences, in order to reduce fish disturbances at every collection time. For every experimental condition, 10 fish were devoted to DNA damage assessments.

\subsection{Chemical analyses}

Water samples were collected several times a day during acclimatization and exposure periods. In the same way, remaining tissues of fish after blood sampling were acid wet digested in open tubes in order to measure major ion and uranium concentrations in fish. Major anion concentrations were analysed in water samples by ionic chromatography (Dionex DX-120, Sunnyvale, CA, USA) while cation and uranium concentrations were measured after $2 \%$ [v/v] $\mathrm{HNO}_{3}$ acidification by means of inductively coupled plasma-atomic emission spectrometry (limit of uranium detection of $10 \mathrm{nmol} / \mathrm{L}$; Optima 4300DV, Perkin-Elmer, USA). 


\subsection{Fish blood sampling}

At every sampling time, 10 fish per tank were collected in order to perform genotoxic analyses on blood cells. For that, fish were captured and immediately pinned on a dissection board, ventral face upwards. Then, a deep incision was performed just below the opercula to release the cardiac cavity. This incision generally induced a rather significant bleeding, sufficient to take several $\mu \mathrm{L}$ of blood using a micropipette with a pre-heparinized tip. Blood sample was then diluted in $250 \mu \mathrm{L}$ of a cryoprotective solution (250 mM sucrose, $40 \mathrm{mM}$ sodium citrate, 5\% DMSO, pH set to 7.6 with $1 \mathrm{M}$ citrate) and immerged into liquid nitrogen. Fish were then sacrificed (by cutting spinal cord) before being weighed. All biologic samples (blood samples and whole body) were stored at $-80^{\circ} \mathrm{C}$ and analysed within few weeks.

\subsection{Genotoxicity assessment}

DNA damage level assessed through two different assays, both of them estimating DNA strand breaks.

\subsubsection{Comet assay}

The comet assay was performed according to the protocol of Devaux et al. [6], a slightly modified version of the procedure described by Singh et al. [7]. Low melting point agarose was mixed with an equal volume of cell suspension (adjusted to about $1.10^{6}$ cells $/ \mathrm{mL}$ ) and laid on a microscope slide (previously coated with normal agarose). Mixture was then covered with a coverslip in order to be uniformly spread out. After polymerization on a cooled metal tray, the coverslips were removed and a second layer of low melting point agarose was added as previously described. After removal of the coverslips, the slides were placed at $4^{\circ} \mathrm{C}$ for $1 \mathrm{hr}$ in a freshly prepared lysing solution (15 mL DMSO, $1.5 \mathrm{~mL}$ triton $\mathrm{X}-100,135 \mathrm{~mL}$ of a stock solution (2.5 M NaCl, 0.1 M EDTA, 0.01 M Tris, pH set to 10 with $\mathrm{NaOH}$ )). From this step to the end of the electrophoresis, the slides were kept in the dark or under dim red light. After the lysis, slides were transferred to an electrophoresis tank filled with freshly prepared buffer (0.3 M NaOH, $1 \mathrm{mM}$ EDTA). DNA was allowed to unwind for 40 min before starting electrophoresis $(20 \mathrm{~V}, 300 \mathrm{~mA}, 24 \mathrm{~min})$. Then, the slides were neutralized with a freshly prepared neutralization buffer (0.4 M Tris-HCl, $\mathrm{pH}$ 7.5) before being dehydrated $10 \mathrm{~min}$ in absolute ethanol to be stored at room temperature. For microscopic observations, slides were stained with $50 \mu \mathrm{L} 0.05 \mathrm{mM}$ ethidium bromide solution. DNA damage was quantified as tail length value using Komet 4.0 software.

\subsubsection{Flow cytometry}

DNA fragmentation assessment with flow cytometry was based on the relaxation of DNA supercoils in presence of strand breaks, involving an increase of nucleoid volume. Measurement of DNA damage was achieved by analysing the forward light scatter signal emitted by nucleoid passage through the laser beam, and detected in a specific cytometer channel referred as FSC. First stage of the procedure consisted in obtaining $300 \mu \mathrm{L}$ of monodisperse nucleoid suspensions. It was achieved by mixing one-third volumes of cell suspension with a lysing solution (1 M NaCl, $10 \mathrm{mM}$ EDTA, $10 \mathrm{mM}$ Tris, $0.2 \%$ triton $\mathrm{X}-100,40 \mathrm{mg} / \mathrm{L}$ propidium iodide, $\mathrm{pH}$ set to 8.0 with $\mathrm{NaOH}$ ) as described by Wang et al., [8]. Propidium iodide, a fluorochrome, was included in the lysing solution in order to discriminate nucleoids among the whole of the events detected. The sample tubes were kept in ice to reduce effects of temperature change. During analysis, nucleoid suspensions (obtained after 15 min of lysis) were run at a moderate flow rate. Sample collection time was about $20 \mathrm{~s}$, depending on sample concentration. The data were then analysed with the Lysis II program and the mean FSC was taken as a measure of nucleoid size. 


\subsection{Statistical analyses}

All statistical tests run under Statistica 6.0 software (Statsoft, 2002) were non-parametric ones. First of all, Kruskal-Wallis one-way ANOVA on ranks were performed $(\mathrm{p}<0.005)$ and post-hoc Nemenyi tests were used to perform multiple comparisons.

\section{RESULTS}

\subsection{Uranium bioaccumulation in fish}

The evolution of bioaccumulation with both time and uranium waterborne concentration is presented on figure 1.

Statistical analyses revealed that there is a significant effect of uranium concentration on bioaccumulation (Kruskal-Wallis ANOVA p-value < 0.001), bioaccumulation in each group of fish exposed to a given uranium concentration being statistically different from the others (table 1a). Furthermore, time exposure influenced bioaccumulation too (Kruskal-Wallis ANOVA p-value $<0.001$ ), fish sacrificed after 20 days of exposure contained significantly more uranium than those that were sacrificed after a 12- or 36-hour exposure (table 1b).

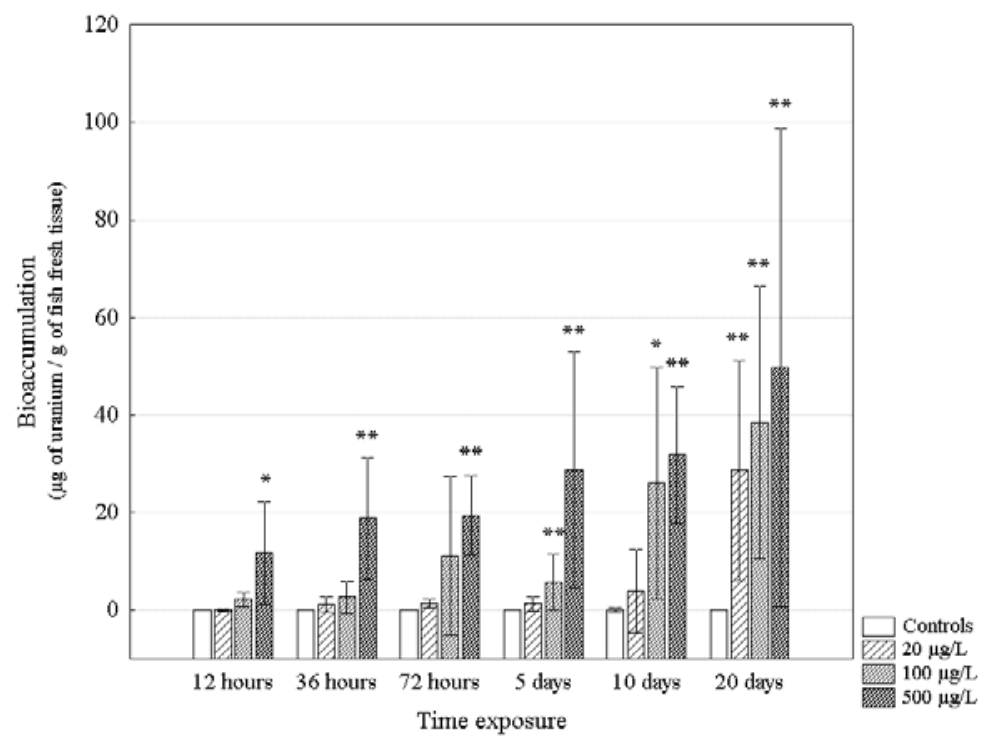

Figure 1. Uranium bioaccumulation in fish (columns and vertical bars denote mean \pm standard deviation, * and ** denote statistical differences with the control group at the same sampling time, p-values being respectively lower than 0.05 and 0.001).

Table 1. Statistical results of Nemenyi tests (* indicate p-values $<0.05$ and ** indicate p-values $<0.001$ ). a. Data corresponding to all sampling times were pooled. b. Data corresponding to all U concentrations were pooled.

\begin{tabular}{|c|c|c|c|c|}
\hline a. & Controls & $20 \mu \mathrm{g} / \mathrm{L}$ & $100 \mu \mathrm{g} / \mathrm{L}$ & $500 \mu \mathrm{g} / \mathrm{L}$ \\
\hline Controls & & $* *$ & $* *$ & $* *$ \\
\hline $20 \mu \mathrm{g} / \mathrm{L}$ & $* *$ & & $*$ & $* *$ \\
\hline $100 \mu \mathrm{g} / \mathrm{L}$ & $* *$ & * & & * \\
\hline $500 \mu \mathrm{g} / \mathrm{L}$ & $* *$ & $* *$ & * & \\
\hline
\end{tabular}

\begin{tabular}{lcccccc} 
b. & 12 hours & 36 hours & 72 hours & 5 days & 10 days & 20 days \\
\hline \cline { 2 - 7 } 12 hours & & n.s. & n.s. & n.s. & n.s. & $* *$ \\
\hline 36 hours & n.s. & & n.s. & n.s. & n.s. & $*$ \\
\hline 72 hours & n.s. & n.s. & & n.s. & n.s. & n.s. \\
\hline 5 days & n.s. & n.s. & n.s. & & n.s. & n.s. \\
\hline 10 days & n.s. & n.s. & n.s. & n.s. & & n.s. \\
\hline 20 days & $* *$ & $*$ & n.s. & n.s. & n.s. & \\
\hline
\end{tabular}




\subsection{Genotoxicity assessment}

\subsubsection{Comet assay}

Considering complete dataset obtained through comet assay analyses, neither significant effect of uranium concentration nor time exposure can be evidenced (Kruskal-Wallis ANOVAs p-values $>0.05$ ). However, some statistically relevant results appear when we focus on results obtained after a 20-day exposure period (figure 2). Indeed, after 20 days, DNA integrity of erythrocytes removed from fish exposed to 100 and $500 \mu \mathrm{g} / \mathrm{L}$ of uranium is significantly lower than DNA integrity in control fish erythrocytes (post-hoc Nemenyi tests p-values respectively lower than 0.05 and 0.001 ), thus revealing a significant effect of uranium exposure (Kruskal-Wallis ANOVA p-value < 0.001).

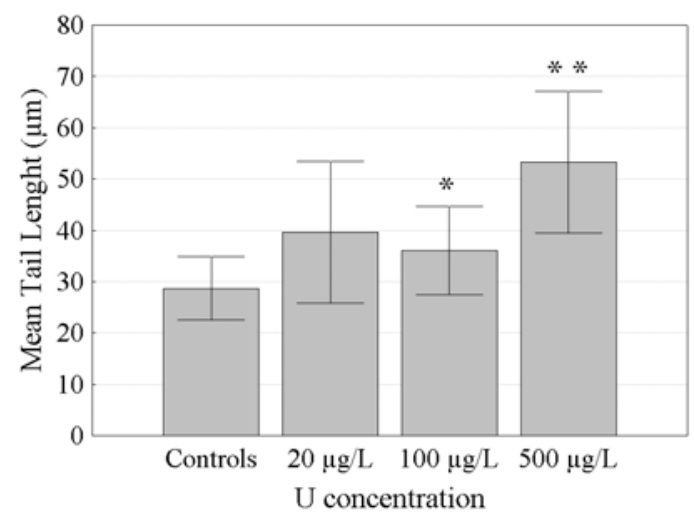

Figure 2. DNA damage assessed by comet assay in erythrocytes of fish exposed to various uranium concentrations for 20 days (columns and vertical bars denote mean \pm standard deviation, * and ** denote statistical differences with the control, p-values being respectively lower than 0.05 and 0.001 ).

\subsubsection{Flow cytometry}

DNA damage assessment by flow cytometry reveals, for all sampling times, a general trend of mean FSC increase along uranium concentrations (i.e. there is a significant effect of uranium concentration on DNA damage, Kruskal-Wallis ANOVA p-value $=0.000$ ) as illustrated, for example, for a 20 day-exposure (figure 3).

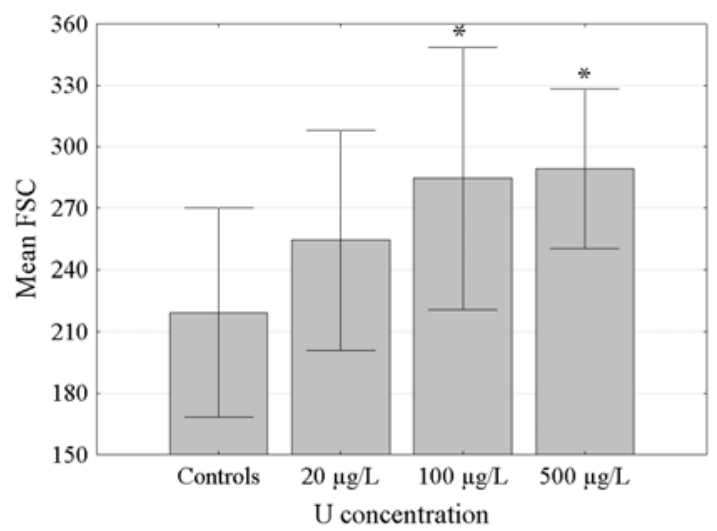

Figure 3. DNA damage assessed by flow cytometry in erythrocytes of fish exposed to various uranium concentrations for 20 days (columns and vertical bars denote mean \pm standard deviation, * denote statistical differences with the control, p-values being lower than 0.05 ). 


\section{DISCUSSION}

Present investigation firstly provides information regarding the accumulation of uranium in zebrafish. Indeed, a significant uranium bioaccumulation in zebrafish at the body level was revealed from the very beginning of the experiment (as soon as after 12 hours at $500 \mu \mathrm{g} / \mathrm{L}$ uranium, as soon as after 5 days at $100 \mu \mathrm{g} / \mathrm{L}$ uranium and after 20 days at $20 \mu \mathrm{g} / \mathrm{L}$ uranium). Though they are not as informative as results obtained from thorough studies on uranium distribution at the fish tissular level [9], these measurements of whole-body contaminant residues are very informative. Moreover, concurrent follow-up of biomarkers carried out in this experiment allows to estimate toxicological significance of this uranium accumulation.

Indeed, biomarkers are used as early warning pollution monitoring tools to signal the onset of sublethal deleterious effects at the physiological, molecular, cellular or subcellular level therefore being able to provide evidence for changes at higher levels of the biological organisation. In this experiment, the loss of DNA integrity has been chosen as an uranium toxicity biomarker due to chemical and radiological properties of this radioactive element. Thus, DNA damage assessment was carried out on fish erythrocytes by comet assay and flow cytometry, both techniques estimating DNA fragmentation level (DNA strand breaks).

Results obtained by both techniques showed that uranium exposure via the direct route appears to induce genotoxicity in erythrocytes of fish exposed to uranium-contaminated water. Among experiments focused on uranium toxicity evaluation, Yazzie et al. [3] also demonstrated uranium-induced genotoxicity (via an in vitro experiment carried out on plasmid DNA). Theses authors hypothesized that hexavalent uranium, as uranyl ion, may have a chemical genotoxicity similar to that of hexavalent chromium (a known human carcinogen), since there are some parallels between their chemistry. They concluded that there are two possible molecular mechanisms that could result in a uranium chemically induced strand breaks: indirectly by free radical generation (Fenton type chemistry) or through direct interactions. In the case of free radical mechanism, catalytic cycling of uranium between hexavalent and tetravalent uranium may induce $\mathrm{H}_{2} \mathrm{O}_{2}$ liberation. Reaction of $\mathrm{H}_{2} \mathrm{O}_{2}$ with tetravalent uranium may then generate a DNA-damaging hydroxyl radical. On the other hand, a direct interaction for uranyl cation and DNA can be explained by a uranyl-complex that may interact with the negatively charged DNA phosphate backbone, resulting in DNA hydrolysis. Others authors [10] focused their in vitro experiments on uranium-catalyzed oxidative DNA damages. They confirmed that uranium might cause DNA damage through the oxidative pathway, uranium acting as a catalyst of biochemical reactions yielding reactive oxygen species. Furthermore, uranium can mimic Fe in the Fenton reaction so that chemically generated $\mathrm{OH}^{*}$ are significantly greater than radioactively generated $\mathrm{OH}^{*}$.

Irrelevant to these mechanistic considerations that cannot be discussed as regards our in vivo results, we can nevertheless try to draw a parallel between bioaccumulation and genotoxicity of uranium. Indeed, we can notice that DNA damages were only detected in erythrocytes of fish that accumulated significant amounts of uranium in their tissues.

\section{CONCLUSION \& PERSPECTIVES}

Considering results obtained through this short-term experiment, we can conclude that aqueous uranium exposure did induce early changes in zebrafish. First of all, uranium can be accumulated in relatively large amounts (from 50 to $100 \mu \mathrm{g} / \mathrm{g}$ of fresh tissues). Moreover, for high level of exposure concentrations, DNA damage biomarkers revealed a statistically significant genotoxic effect of uranium in erythrocytes. However, it would be of large interest to estimate genotoxic potential of uranium towards organs supposed to be more specific targets than blood tissue. Gills and liver have been selected as such key organs, respectively with regard to exposure route and chemical properties of uranium. Thereby, fish concerned by blood sampling have also been dissected, gill and liver tissues being removed and stocked at $-80^{\circ} \mathrm{C}$ in a cryopreservative solution. Genotoxicity analyses are still in progress. 
Furthermore, genotoxic properties of uranium being linked to its ability to generate reactive oxygen species, specific biomarker responses should be investigated. That is the reason why, concurrently to the experiment previously described, 400 other fish have been sampled for the study of oxidative stress biomarkers. Two kinds of biomarkers were chosen (i) enzymatic antioxidants (catalase, superoxide dismutase and glutathione peroxidase, which belong to the cellular antioxidant system that counteracts the toxicity of reactive oxygen species) and (ii) a non-enzymatic antioxidant (glutathione). Fish have been dissected, gill and liver tissue being removed and S9 fractions prepared in a specific cryopreservative solution and stocked at $-80^{\circ} \mathrm{C}$. These analyses, still in progress, will probably provide additional information to better understand the toxicity of uranium.

Finally, uranium as every heavy metal is suspected to be a neurotoxic compound, brain collections have thus been realized and S9 preparations stocked at $-80^{\circ} \mathrm{C}$, in order to later analyse the activity of acetylcholinesterase, an enzyme playing a role in neurotransmission.

\section{References}

[1] Bleise A., Danesi P.R. and Burkart W., J Environ Radioactiv 64 (2003) 93-112.

[2] Hartwig A., Biometals 8 (1995) 3-11.

[3] Yazzie M., Gamble S.L., Civitello E.R. and Stearns D.M., Chem Res Toxicol 16 (2003) 524-530.

[4] Jones D., Domotor, S., Higley K., Kocher D. and Bilyard G., J Environ Radioactiv 66 (2003) 19-39.

[5] Spitsbergen J.M. and Kent M.L., Toxicol Pathol 31 (2003) 62-87.

[6] Devaux A., Pesonen M. and Monod G., Toxicol In Vitro 11 (1997) 71-79.

[7] Singh N.P., McCoy M.T., Tice R.R. and Schneider E.L., Exp Cell Res 175 (1988) 184-191.

[8] Wang J., Hyun W., Lmborn K. and Deen D.F., Cancer Res 56 (1996) 154-157.

[9] Cooley H.M., Klaverkamp J.F., Aquat Toxicol 48 (2000) 477-494.

[10] Miller A.C., Stewart M., Brooks K., Shi L. and Page N., J Inorg Biochem 91 (2002) 246-252. 